\title{
Single nucleotide polymorphism (SNP) discovery in duplicated genomes: intron-primed exon-crossing (IPEC) as a strategy for avoiding amplification of duplicated loci in Atlantic salmon (Salmo salar) and other salmonid fishes
}

\author{
Heikki J Ryynänen*1 and Craig R Primmer ${ }^{1,2}$
}

Address: ${ }^{1}$ Department of Biological and Environmental Sciences, University of Helsinki, P.O. Box 65, FIN-00014 University of Helsinki, Finland and ${ }^{2}$ Department of Biology, University of Turku, FIN-20014, Finland

Email: Heikki J Ryynänen* - Heikki.J.Ryynanen@helsinki.fi; Craig R Primmer - craig.primmer@utu.fi

* Corresponding author

Published: 27 July 2006

BMC Genomics 2006, 7:192 doi:10.1186/147|-2164-7-192

This article is available from: http://www.biomedcentral.com/l47/-2164/7/192

(c) 2006 Ryynänen and Primmer; licensee BioMed Central Ltd.

This is an Open Access article distributed under the terms of the Creative Commons Attribution License (http://creativecommons.org/licenses/by/2.0), which permits unrestricted use, distribution, and reproduction in any medium, provided the original work is properly cited.
Received: 06 June 2006

Accepted: 27 July 2006

\begin{abstract}
Background: Single nucleotide polymorphisms (SNPs) represent the most abundant type of DNA variation in the vertebrate genome, and their applications as genetic markers in numerous studies of molecular ecology and conservation of natural populations are emerging. Recent large-scale sequencing projects in several fish species have provided a vast amount of data in public databases, which can be utilized in novel SNP discovery in salmonids. However, the suggested duplicated nature of the salmonid genome may hamper SNP characterization if the primers designed in conserved gene regions amplify multiple loci.

Results: Here we introduce a new intron-primed exon-crossing (IPEC) method in an attempt to overcome this duplication problem, and also evaluate different priming methods for SNP discovery in Atlantic salmon (Salmo salar) and other salmonids. A total of 69 loci with differing priming strategies were screened in S. salar, and 27 of these produced $\sim 13 \mathrm{~kb}$ of high-quality sequence data consisting of 19 SNPs or indels (one per $680 \mathrm{bp}$ ). The SNP frequency and the overall nucleotide diversity $\left(3.99 \times 10^{-4}\right)$ in $S$. salar was lower than reported in a majority of other organisms, which may suggest a relative young population history for Atlantic salmon. A subset of primers used in cross-species analyses revealed considerable variation in the SNP frequencies and nucleotide diversities in other salmonids.

Conclusion: Sequencing success was significantly higher with the new IPEC primers; thus the total number of loci to screen in order to identify one potential polymorphic site was six times less with this new strategy. Given that duplication may hamper SNP discovery in some species, the IPEC method reported here is an alternative way of identifying novel polymorphisms in such cases.
\end{abstract}

\section{Background}

The diversification of the variety of molecular markers available has been an important development in the field of genetics over the past two decades [1], with one of the more recent additions to the 'molecular toolbox' being single nucleotide polymorphisms (SNPs): a variant of traditional DNA sequencing which potentially enables highthroughput analysis of numerous independent (mostly) 
bi-allelic DNA sequence polymorphisms. The increase in the range of molecular markers partly stems from the realisation that no particular marker type is ideal for all situations, and SNPs are no exception to this. Their beneficial features include having a relatively simple mutation model $[2,3]$ and a high abundance in the genome (see e.g. [4]). Furthermore, the fact that SNPs occur in coding regions enables assessment of polymorphisms potentially directly affecting the phenotype [5]. On the other hand, as SNPs are normally bi-allelic markers, more loci are needed to obtain sufficient statistical power in certain analyses (see e.g. [6]) and allele frequencies of SNPs are usually skewed in population level analyses [7]. In theory, the limited amount of information in a single SNP locus can be compensated by increasing the number of loci screened, and several high-throughput procedures have been developed to facilitate this need (see $[5,8]$ ). Overall however, it is clear that SNPs are an important class of molecular markers for genomics research and can potentially be applied in a wide range of studies.

While the recognized benefits of SNPs have accelerated their use in studies of model organisms [9-13], the application of SNPs in genetic studies of wild species has been relatively rare. Their potential use in animal genetics has been reviewed by Vignal et al. [14], presenting the usefulness of SNPs in, e.g., parentage assignment, animal tagging (see also [15]) and especially in QTL mapping, but similar studies with natural organisms have only been reported recently, most likely due to a lack of suitable markers. Recently however, new SNP discovery strategies (e.g. [16]) have resulted in characterizations of SNPs in many natural populations of vertebrates to address several evolutionary, ecological and conservation issues. For example, SNPs have been applied for the identification of cryptic vole species [17], to investigate the level of genome introgression in a passerine bird hybrid zone $[18,19]$, and to study the population genetics of wolves [20].

SNP discovery in model organisms has primarily been performed by comparing genomic information of multiple individuals in the public databases in order to identify putative polymorphic sites (e.g. [21]). This has been a useful approach for species with a wealth of nuclear sequence data available, but is not a very feasible method for the majority of non-model organisms. In species with little published sequence data available, SNP identification has been carried out by sequencing random DNA fragments (e.g. $[16,22,23])$, or by using a targeted gene approach where primers have been designed in conserved regions of orthologous gene sequences from closely related species to amplify less conserved regions like introns, generally termed 'comparative anchor tagged sequences' ('CATS') or the 'exon-primed intron-crossing' ('EPIC') method (e.g. $[16,24-28])$. Again, this latter type of SNP discovery may be challenging if the entire taxa of interest lacks published sequence data. In recent years, however, large-scale sequencing and EST projects have provided usable data for a great variety of new species and a particular increase can be seen in fish species, due in part to their potential use as models in environmental genomics [29] as well as the broad variety of species of aquaculture importance. The total number of SNPs needed to trace different strains within a species has been estimated with salmonid fish [30] and, even individual identification would be possible if the population and/or species-specific SNPs were characterized as has been conducted in wolves [20]. Furthermore, Glaubitz et al. [6] estimated in a simulation study that about five times more SNPs than microsatellites are needed to determine pair-wise genetic relationships.

Atlantic salmon (Salmo salar) has been one of the most widely studied fish species in recent decades due to its importance for aquaculture and conservation, but extensive SNP characterization studies with this salmonid species have been scarce. Recently, large-scale sequencing, EST and BAC library projects have made a large amount of data available in the public databases for S. salar (see [3133]; and also [34-36]). These genomic resources have given rise to the first exploitation of EST databases for SNP discovery (unpublished data, Hayes et al). However, Hayes et al. (unpublished data) speculated that a proportion of the potential SNPs observed in S. salar EST sequences could in fact be a consequence of ancient duplication events in the salmonid genome, and some of the 2,507 putative EST-based SNPs found could actually be sequence differences between ancestral duplicates (i.e. paralogues) rather than true SNPs. Similarly, genome duplication has also been suggested to affect SNP identification in a recent study of Pacific salmon (Oncorhynchus tshawytscha, O. nerka, and O. keta) [37], where one-third of the analyzed loci were suggested to be paralogue sequence variants rather than true SNPs. Potentially sequence differences between duplicons rather than SNPs (see [38]) may emerge especially when the more highly conserved regions (i.e. exons) of the genes are used for primer design as this increases the risk of amplifying both paralogs of the same locus. Thus far, such exon-focused methods (e.g. EPIC) have been exploited in most of the SNP discovery surveys, and no study exists where the more variable, noncoding segments of the genes (e.g. introns) have been utilized to design specific primers aimed at binding to only one of the duplicated loci. This is probably due to fact that more than one sequence copy of the particular gene seldom exists in the databases and not much is known about the extent of potential duplicated genes in different species. However, intron sequences of one known duplicated gene in salmonids - growth hormone - have been used as a source of variation for phylogenetic and population studies [39-41], indicating that the divergence in introns 
could be sufficient for a discriminative priming strategy between putative paralogs in salmonid species.

The aim of this study was to characterize potential SNPs in the Atlantic salmon genome using gene sequence data for salmonids and other teleost species obtained from GenBank [42]. Initially, PCR primers were designed by utilizing the exonic regions of salmonid or other teleost species (EPIC). However, on observing that numerous duplicated genes had likely been amplified, a new method - termed intron-primed exon-crossing (IPEC) - was developed to circumvent this problem, whereby primers were designed in more variable intronic regions of salmonid genes. The feasibility of this new priming method to avoid amplifications of potential duplicated loci was evaluated, and the proportion of conserved duplicated loci assessed. Polymorphism was assessed by sequencing the fragments of individuals originating from 15 salmon populations spanning the species range. Furthermore, a subset of primers was tested with brown trout (Salmo trutta), arctic char (Salvelinus alpinus) and grayling (Thymallus thymallus) to investigate the usefulness of these loci to produce crossspecies sequence data from other salmonids.

\section{Results}

Exon- vs. intron-primed SNP discovery strategies

Out of a total of 47 loci for which primers were designed using the EPIC strategy, only 14 (30\%) primer pairs produced PCR products suitable for direct sequencing - i.e., PCR amplification resulted in a single, strong band as visualized by agarose gel electrophoresis (Table 1a). The vast majority of these (13 out of 14) were loci where primer sequences were designed using salmonid exonic sequences. However, of these 13 clear PCR products, highquality sequence was obtained for only 4 loci, with the sequences of other loci resembling that expected if multiple sequences were present in the same reaction. For primers based on exonic sequences of non-salmonid teleosts, the proportion of loci for which a single clear PCR product was obtained was much lower (4\%). However, following re-PCR of one of the multiple bands observed, high-quality sequence was obtained for a similar overall proportion of loci to that for exonic primers based on salmonid sequences ( $24 \%$ vs. $18 \%$ : Table $1 \mathrm{a})$.

In comparison, the success rate of intron-primed exoncrossing (based on salmonid intron sequences) was considerably higher: a single clear PCR product was obtained for 21 of 22 loci $(95 \%)$ and high-quality sequences were obtained for 17 of these $(77 \%)$ - i.e., a success rate almost four times higher than that obtained using the EPIC approach $\left(\chi^{2}=7.771\right.$, d.f. $\left.=1, P=0.005\right)$. In addition, of the loci for which high-quality sequence was obtained, the proportion of loci in which polymorphism was identified was higher in IPEC-derived sequences (47\% vs.
$30 \%)$. This difference is even more striking when considering the proportion of polymorphic loci in the total number of loci initially tested (36\% vs. $6 \%$ ). In other salmonid species the proportion of loci for which sequences were successfully obtained ranged from $12 \%$ in grayling to $60 \%$ in brown trout (Table $1 \mathrm{~b}$ ). Sequences of all loci have been deposited in GenBank with the accession numbers [GenBank:DQ834872-DQ834885]. Details of the loci for which high-quality sequence data were not obtained are available on request.

\section{Level of genetic diversity in the gene sequences of Atlantic salmon and other species}

In total, high quality sequences were obtained for 27 loci with a total of 12,911 bp. Nineteen polymorphic sites were observed in 10 loci which translates to an average of one SNP per 680 bp in the S. salar genome (Table 2, Additional file 2). The observed frequency is one of the lowest reported for any fish species and lower than the frequencies reported in the majority of multi-locus studies in different taxonomic groups; only some mammalian and avian studies exhibited lower estimates (Figure 2). The distribution of polymorphism among the loci was however highly skewed, with no variation observed in $~ 60 \%$ of loci (Table 2, Figure 3). The nucleotide diversity of individual loci ranged from 0 to $17.5 \times 10^{-4}$ and over all loci was $3.99 \times 10^{-4}$ (Table 2, Figure 3 ). Twelve of the polymorphic sites were located in intronic regions of verified salmonid genes whereas none occurred in the exons (Table 2). This results in the nucleotide diversity estimates of 6.7 $\times 10^{-4}(1 \mathrm{SNP} / 405 \mathrm{bp})$ for introns and $<1.9 \times 10^{-4}$ for exons (less than $1 / 1448 \mathrm{bp}$ ) respectively. As a comparison, the level of variability in transferrin, a gene suggested to have been affected by the forces of diversifying selection in salmonid fishes, was also assessed (locus sTf, Additional files 1 and 2). The nucleotide diversity of this gene was many times higher $\left(46.0 \times 10^{-4}\right)$ than that observed in other genes. Furthermore, three of the five SNPs (1/77 bp) observed in this gene occurred in exonic sequences, two of which were non-synonymous.

Considering other salmonid species, the overall nucleotide diversity for $\mathrm{S}$. alpinus was similar to $\mathrm{S}$. salar but the estimates were about six times higher for T. thymallus and $\mathrm{S}$. trutta (Table 2). Furthermore, the frequency of polymorphic sites was much higher in T. thymallus ( $1 / 144 \mathrm{bp})$ and $S$. trutta $(1 / 153 \mathrm{bp})$ compared with $S$. salar, but almost identical for $S$. alpinus (1/695 bp). Contrary to $S$. salar, the transferrin gene in $S$. trutta (396 bp sequenced) exhibited no variation among the analyzed populations; instead, four SNPs were located in the exonic regions of other genes, also changing the reading frame of tap $2 \mathrm{~A}$ gene (Table 2). 
Table Ia: Summary of the success of candidate SNP loci identification with different priming approaches in (a) Atlantic salmon.

\begin{tabular}{|c|c|c|c|c|}
\hline \multirow[b]{2}{*}{ Process description } & \multicolumn{3}{|c|}{ PCR primer design strategy } & \multirow[b]{2}{*}{ Total } \\
\hline & $\mathrm{EPIC} \mathrm{I}$ a & EPIC II b & IPEC c & \\
\hline \multicolumn{5}{|l|}{ S. salar } \\
\hline No. loci tested & 22 & 25 & 22 & 69 \\
\hline No. loci producing clear PCR product & $13 \mathrm{~d}$ & I e & 21 & 36 \\
\hline No. loci successfully sequenced & 4 & 6 & 17 & 27 \\
\hline No. polymorphic loci & 0 & 3 & 8 & 11 \\
\hline
\end{tabular}

a - primers in exons of salmonid genes

$\mathrm{b}$ - primers in exons of other teleost genes

$c-$ at least one primer in intron regions of salmonid genes

$\mathrm{d}$ - in five loci two distinct PCR bands were observed and four loci produced a smear

e-most of the primers produced several PCR bands and thus re-amplifications were needed (see Methods)

\section{Discussion}

The results of this study have important implications for SNP discovery in non-model species with ancestrally duplicated genomes. Exon-targeted primers using sequence data from the same or closely related taxa which have previously been used in SNP characterization studies with non-model species $[16,22,26,37]$ were relatively unsuccessful in Atlantic salmon compared with the IPEC approach proposed here, where less conservative gene regions - i.e., introns - were the target sequences for primer design. The reduced success of the EPIC approach for SNP discovery is most likely due to the duplicated nature of the salmonid genome. This genomic duplication is suggested to have taken place in the ray-finned fish lineage after its divergence from tetrapods (reviewed in [43]) and additional, more recent polyploidization events have also been detected in the salmonid sublineage (see [44]). The subsequent re-diploidization event in the salmonid genome has generated duplicated paralogs, which may diverge from each other due to the relaxation of purifying selection in one of the copies (reviewed in [45]). Thus, assuming that diverged introns evolve even more rapidly due to lower selective pressure, the amplification of potential duplicates could be minimized by focusing on those regions for PCR primer design.

Indeed in S. salar, this new intron-targeted IPEC method clearly outperformed the widely used EPIC (or CATS) approach, which utilizes conserved gene regions in crossspecies applications. The proportion of screened loci that

Table I b: Summary of the success of candidate SNP loci identification with different priming approaches in (b) other salmonids.

\begin{tabular}{|c|c|c|c|c|}
\hline \multirow[b]{2}{*}{ Process description } & \multicolumn{3}{|c|}{ PCR primer design strategy } & \multirow[b]{2}{*}{ Total } \\
\hline & EPIC I a & EPIC II b & IPEC c & \\
\hline \multicolumn{5}{|l|}{ T. thymallus } \\
\hline No. loci tested & 22 & - & 20 & 42 \\
\hline No. loci producing clear PCR product & $11 \mathrm{~d}$ & & 4 & 16 \\
\hline No. loci successfully sequenced & 4 & - & 2 & 5 \\
\hline No. polymorphic loci & 3 & - & 2 & 5 \\
\hline \multicolumn{5}{|l|}{ S. trutta } \\
\hline No. loci tested & - & - & 10 & 10 \\
\hline No. loci producing clear PCR product & - & - & 8 & 8 \\
\hline No. loci successfully sequenced & - & - & 6 & 6 \\
\hline No. polymorphic loci & - & - & 4 & 4 \\
\hline \multicolumn{5}{|l|}{ S. alpinus } \\
\hline No. loci tested & - & - & 10 & 10 \\
\hline No. loci producing clear PCR product & - & - & 5 & 5 \\
\hline No. loci successfully sequenced & - & - & 3 & 3 \\
\hline No. polymorphic loci & - & - & I & I \\
\hline
\end{tabular}

a - primers in exons of salmonid genes

b - primers in exons of other teleost genes

$c-$ at least one primer in intron regions of salmonid genes

$\mathrm{d}-$ in five loci two distinct PCR bands were observed and six loci either produced a smear or no amplification was observed 


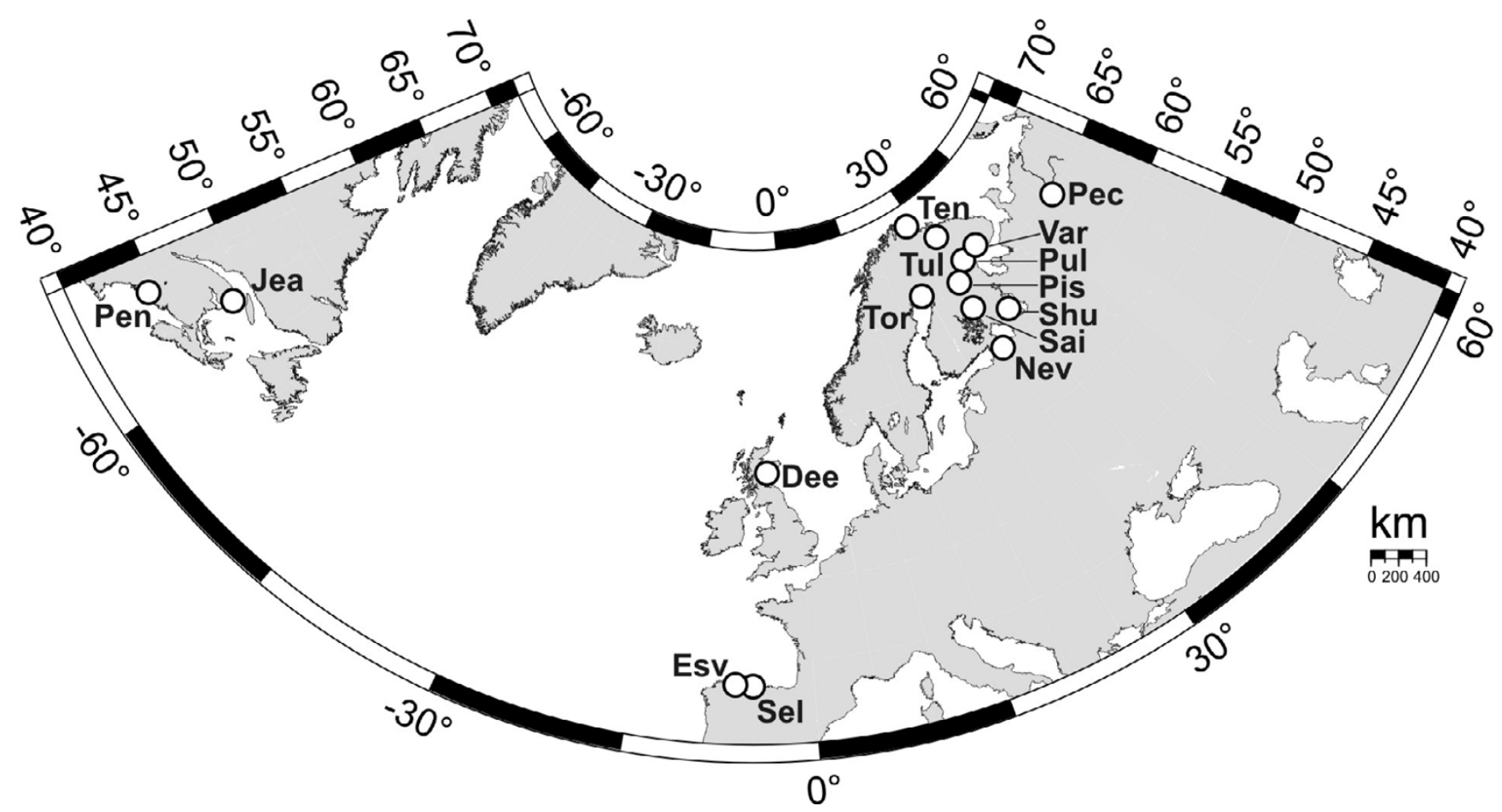

Figure I

Locations of the I 5 Atlantic salmon population analyzed in this study. One individual was sampled from each population and their abbreviations were: Penobscot, USA (Pen), St Jean, Canada (Jea); Dee River, UK (Dee); Esva River, Spain (Esv); Sella River, Spain (Sel), Tenojoki River, Finland (Ten); Tuloma River, Russia (Tul); Tornionjoki River, Finland (Tor); Pechora River, Russia (Pec); Varzuga River, Russia (Var); Pulonga River, Russia (Pul); Pistojoki River, Russia (Pis), Shuja River, Russia (Shu); Lake Saimaa, Finland (Sai) and Neva River, Russia (Nev).

revealed polymorphism in $S$. salar was around six times higher with the IPEC (36.4\% polymorphic) than the EPIC $(6.4 \%)$ method (Table 1a), suggesting that less effort is needed to yield the same number of SNPs than with the EPIC (or CATS) method [28,37].

Recently, special interest has focused on identifying multisite variation after duplication from ordinary SNPs in humans [46]. Studies with several salmonid species have also speculated that some of the observed polymorphic sites could actually be variation between retained paralogs of duplicated segments rather than true SNPs ([37,38]; unpublished data, Hayes et al). The duplication presumably lowered the success rate of the EPIC primers, especially those designed in salmonid genes (Table 1a), but it may have a minor effect on the novel SNPs identified in this study as the IPEC method produced most of the polymorphic loci $(71 \%$ in total, Table $1 \mathrm{a}-\mathrm{b})$. Therefore, this intron-focused approach should be a feasible method to avoid obtaining potential 'duplicated SNPs' when identifying novel polymorphic loci from the species bearing putative duplicated genomic fragments or even an entire duplicated genome.

The observed nucleotide diversity estimates over all loci in S. salar $\left(3.99 \times 10^{-4}\right)$ was highly similar to that in European humans [9] and about twofold lower than that observed in a larger scale survey with human genome [4]. On the other hand, the estimations are about ten times less than reported in birds [16] or plants [47,48] and about three times less than reported in a recent study of the GH1 gene of $S$. salar [41]. The greater number of base pairs and the number of independent loci sequenced here most likely better represents the overall nucleotide diversity estimate of $S$. salar genome than that observed in a single locus [41]. A lower nucleotide diversity in $S$. salar is further supported by the fact that about $60 \%$ of all analyzed loci showed no variation (Figure 3), and the overall SNP frequency was lower than in the majority of other organisms (Figure 2 and references therein). A lower level of sequence variation could be a consequence of relatively recent colonization of $S$. salar in its present habitats in the 


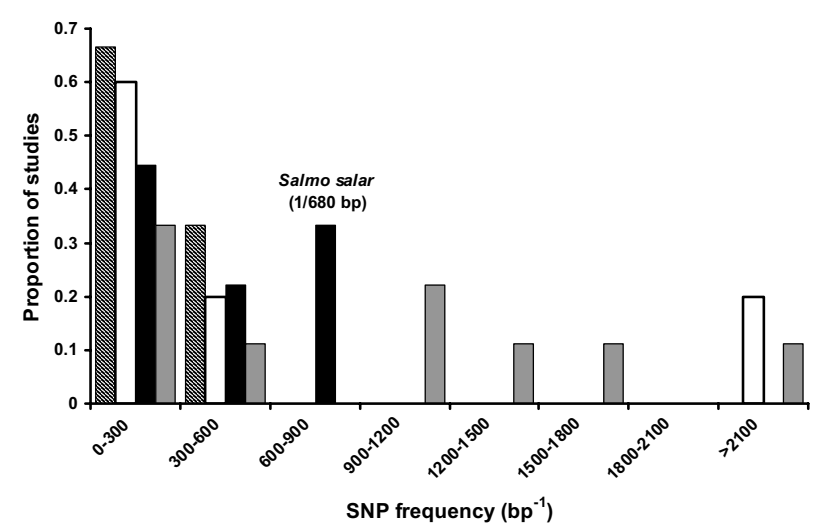

Figure 2

SNP frequencies in four salmonid species observed in this study and from $\mathbf{2 5}$ selected multi-locus studies of various organisms. Different species were split into four taxonomic groups: plants ( $n=6$, hatched bars), birds $(n=5$, white bars), fish ( $n=9$, black bars), and mammals ( $n=9$, grey bars). Estimates were obtained from the following publications: $[4,9,12,16,71]$; [2] and references therein; [20, 23, 37, 72-74]; unpublished data, Hayes et al.

northern hemisphere after the last glaciation about 10 , 000 years ago [49] as such patterns of reduced genetic variability in areas previously glaciated areas has been observed for other northern species (e.g. $[50,51])$

The SNP frequency in non-coding regions was at least threefold higher than coding regions in S. salar, which is to be expected due to the greater selective pressure on exons as observed in a recent human genome study [52]. Studies on disease-associated genes in humans have revealed an even higher proportion of coding SNPs, implying the effects of natural selection $[53,54]$. This may also explain the higher frequency of SNPs in the coding region of the transferrin gene, which plays an important role in resistance to bacterial infection in a variety of organisms and was earlier reported to be under positive selection in $S$. salar [55]. On the contrary, no polymorphisms were detected in the transferrin gene of $S$. trutta, proposing that the effects of selection may vary considerably within lineages. However this could be due to the selection of the transferrin gene region which was sequenced in this study as considerable molecular variation has been reported in the transferrin gene within European S. trutta populations based on electrophoretic screening [56].

The overall SNP frequencies also varied among the salmonid species examined here (between $1 / 144 \mathrm{bp}$ in $T$. thymallus to $1 / 695$ bp in S. alpinus) but were, however, within the range of the SNP frequencies for a range of multi-locus studies with different species (Figure 2 and references therein). The estimates for $S$. salar and $S$. alpinus were in congruence with a previous study on $S$. salar (unpublished data, Hayes et al.), whereas the frequencies for $T$. thymallus and S. trutta were closer to a recent study with Pacific salmon [37]. Furthermore, in S. trutta and T. thymallus the nucleotide diversities were about six times higher than in S. salar or S. alpinus (Table 2). The high level of diversity in $T$. thymallus is consistent with the deep divergence between the evolutionary lineages assessed [57]. However, the high level of diversity in S. trutta is more difficult to explain as all individuals analysed originate from the same evolutionary lineage (the Atlantic lineage) proposed by Bernatchez [58]. However it is important to note that no Finnish S. trutta samples were assessed in the study of Bernatchez [58] and thus additional diversity may be harboured in this region.

\section{Conclusion}

Exploitation of the exponentially increasing amount of gene sequence data in public databases such as GenBank and recent EST projects is a very useful basis for identifying new polymorphic loci from the genomes of nonmodel organisms. Applications of SNPs have already been reported in ecological and conservation studies of natural populations $[17,20,22]$, and these new types of markers have also been used to identify different Atlantic salmon strains [30]. However, as observed in this study, polymorphisms can be biased toward a relatively small portion of loci (Figure 3) thus increasing the effort required to identify a sufficient number of SNPs for ecological and population genetic applications. Based on a simulation study, the need for independent SNPs is fivefold that of microsatellites [6]. Furthermore, in salmonid fish the genome duplication event has been suggested to reduce SNP validation success ([37]; unpublished data, Hayes et al.), a result supported by this study, which may further hinder the development of a large number of independent loci. Therefore, the new IPEC approach introduced here will be a useful way to identify true SNPs for various applications in species with presumably duplicated genomes.

\section{Methods \\ Candidate loci identification}

Initially, candidate sequence fragments were extracted from GenBank using the criteria that they consisted of both exon and intron regions, the intronic regions were 400-600 bp in length to enable a single forward or reverse sequencing read of the particular PCR product, and that there were long enough exonic sequences flanking both sides of the desired intron for PCR primer design. Then, two different EPIC approaches were used in the primer design processes: (I) primers were designed on flanking exonic sequences of $S$. salar or other salmonid genes, or (II) flanking exonic sequences of other teleost 
Table 2: Details of the sequenced fragments and polymorphisms indices found in analysed salmonid fish populations. Overlapping loci from the same gene have been combined as one index. Details of these SNPs have been included the sequences submitted to GenBank with the accession numbers [GenBank:DQ834848-DQ834885].

\begin{tabular}{|c|c|c|c|c|c|c|}
\hline \multirow[b]{2}{*}{ Locus } & \multirow[b]{2}{*}{$\begin{array}{l}\text { Source species } \\
\text { a }\end{array}$} & \multicolumn{5}{|l|}{ Focal species } \\
\hline & & $\begin{array}{l}\text { Sequence length } \\
\text { (bp) }\end{array}$ & $\begin{array}{l}\text { No. individuals } \\
\text { screened }\end{array}$ & Intronic/exonic region (bp) & No. SNPs and/or indels & Theta $\left(\times 10^{4}\right)$ \\
\hline \multicolumn{7}{|l|}{ S. salar } \\
\hline U2A' (ii and iv) & Ssa & 609 & 14 & $529 / 80$ & 0 & - \\
\hline SS-II (i and ii) & Ssa & 540 & 15 & $403 / 137$ & 0 & - \\
\hline HMG-I (ii) & Omy & 505 & 15 & $475 / 30$ & 0 & - \\
\hline TGF-beta ( $\mathrm{i}$ and ii) & Omy & 791 & 15 & $489 / 302$ & I & 3.2 \\
\hline HMG-I (iii) & Omy & 540 & 15 & $394 / 146$ & 0 & - \\
\hline Ran I (iii) & Ssa & 501 & 10 & $416 / 85$ & 3 & 16.6 \\
\hline sGnRH (ii) & Ssa & 562 & 15 & $481 / 81$ & 0 & - \\
\hline GDF-8 & Ssa & 497 & 11 & $497 / 0$ & 2 & 11.0 \\
\hline FGF6 (ii) & Omy & 557 & 11 & $483 / 74$ & 2 & 9.9 \\
\hline Vtg (ii) & Omy & 447 & 15 & $277 / 170$ & 0 & - \\
\hline ras-I(ii) & Omy & 536 & 5 & $536 / 0$ & 0 & - \\
\hline tnfa (ii) & Omy & 522 & 13 & $462 / 60$ & 0 & - \\
\hline IL-I beta 2 & Omy & 399 & 10 & $399 / 0$ & I & 7.1 \\
\hline RAG-I & Omy & 563 & 15 & $563 / 0$ & 0 & - \\
\hline$c-m y c$ & Omy & 578 & 15 & $328 / 250$ & I & 4.4 \\
\hline$D(2) R$ & Omy & 483 & 14 & $483 / 0$ & 0 & - \\
\hline $\mathrm{IgMh}$ & Sal & 518 & 15 & $518 / 0$ & 2 & 9.7 \\
\hline rps24 & Tru & $776^{c}$ & 11 & unknown & 5 & 17.5 \\
\hline CCBLI & Tru & $298 d$ & 4 & unknown & 0 & - \\
\hline epn b & Cca & 359 e & 5 & unknown & 0 & - \\
\hline epn(2) b & Cca & $297^{f}$ & 9 & unknown & 0 & - \\
\hline ssg(i) & Dre & $470 \mathrm{~g}$ & 15 & unknown & I & 5.4 \\
\hline EFla & Dre & $729 \mathrm{~h}$ & 5 & unknown & I & 4.8 \\
\hline hox & Dre & $834 \mathrm{~h}$ & 9 & unknown & 0 & - \\
\hline Total & & 12911 & $11.7^{i}$ & $7700 / / 448 i$ & 19 & 3.99 \\
\hline \multicolumn{7}{|l|}{ S. trutta } \\
\hline SS-II (ii) & Ssa & 385 & 5 & $353 / 32$ & 1 & 9.2 \\
\hline tap2A (ii) & Ssa & 367 & 5 & $238 / 129$ & $6 \mathrm{k}$ & 57.8 \\
\hline HMG-I (iii) & Omy & 540 & 4 & $394 / 146$ & 0 & - \\
\hline TGF-beta (ii) & Omy & 487 & 5 & $336 / 151$ & 2 & 14.5 \\
\hline tnfa (ii) & Omy & 514 & 4 & $454 / 60$ & 61 & 45.0 \\
\hline Total & & 2293 & $4.6^{i}$ & $|775 / 5| 8$ & 15 & 24.1 \\
\hline \multicolumn{7}{|l|}{ T. thymallus } \\
\hline SS-II (i) & Ssa & 525 & 5 & $416 / 109$ & 5 & 33.7 \\
\hline U2A' (ii) & Ssa & 373 & 5 & $327 / 46$ & 4 & 37.9 \\
\hline TGF-beta (i and ii) & Omy & 743 & 5 & $441 / 302$ & 3 & 14.3 \\
\hline RAG-I & Omy & 376 & 5 & $376 / 0$ & 2 & 18.8 \\
\hline Total & & 2017 & $5 i$ & $1560 / 457$ & 14 & 24.5 \\
\hline \multicolumn{7}{|l|}{ S. alpinus } \\
\hline SS-II (ii) & Ssa & 354 & 5 & $322 / 32$ & 0 & - \\
\hline HMG-I (iii) & Omy & 524 & 5 & $378 / 146$ & 2 & 13.5 \\
\hline tnfa (ii) & Omy & 512 & 5 & $452 / 60$ & 0 & - \\
\hline total & & 1390 & $5 i$ & $1152 / 238$ & 2 & 5.1 \\
\hline
\end{tabular}

a - Cca, Cyprinus carpio; Dre, Danio rerio; Omy, Oncorhynchus mykiss; Sal, Salvelinus alpinus; Ssa, Salmo salar; Tru, Takifugu rubripes

$\mathrm{b}$ - two separate PCR fragments extracted from the agarose gel were sequenced using the same primer pair

c- $92 \%$ (346/376 bp) homology to S. salar zonadhesin-like gene, promoter region [GenBank:AY785950]

d - $94 \%$ (228/242 bp) homology to O. mykiss multi tissue cDNA clone [GenBank:BX076795]

e- $98 \%$ (195//98 bp) homology to S. salar white muscle cDNA library clone [GenBank:CK899537]

$f-93 \%$ (230/245 bp) homology to S. salar mixed tissue cDNA clone [GenBank:CA055I3I]

g-95\% (334/350 bp) homology to S. salar kidney cDNA library clone [GenBank:CK886988]

$\mathrm{h}$ - no homologous sequences found after Blast search

$i-$ an average number of individuals screened over all loci

$\mathrm{j}-$ the sum of intronic/exonic regions do not include 'unknown' sequences in S. salar

$\mathrm{k}$ - three SNPs occurred as non-synonymous form in exonic regions

$\mathrm{I}$ - one polymorphic site was located in synonymous site of exonic region 


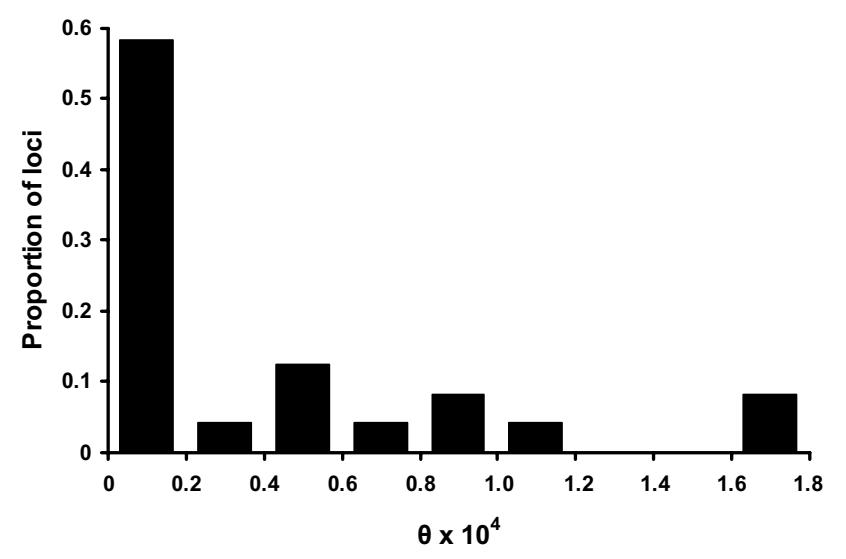

Figure 3

Frequency distribution of nucleotide diversities $(\theta)$ observed in the sequences of 24 independent loci (see Table 3) investigated in Atlantic salmon.

fishes were used to design oligonucleotides. In addition, when the success rate of these exon-primed primers was seen to be low, a new intron-primed exon-crossing method was introduced (hereafter called IPEC) where at least one primer was designed in the intronic regions of salmonid fish genes (Additional file 1) in an attempt to avoid amplification of potential paralogues. It should be noted that some of the primers designed in introns amplified only intronic sequences without spanning any exonic regions (6/24 in S. salar; Table 1a) but for the sake of uniformity all these fragments are referred as IPEC loci. Based on the criteria described above, a total of 69 PCR primer pairs (Additional file 1) predicted to amplify fragments of 400-700 bp in total length were designed using the program Primer3 [59].

\section{Sampled individuals and populations}

One S. salar individual per population from each of 15 populations covering a wide range of the species' distribution in Europe and North America were assessed for polymorphism (Figure 1). Of these, Rivers Pistojoki and Shuja and Lake Saimaa exhibit a non-anadromous migration behaviour, whereas all others were anadromous populations. Furthermore, the Lake Saimaa and River Neva samples were of hatchery origin. Different subsets of primers were also tested with five other salmonid (S. trutta, S. alpinus and T. thymallus) populations (one individual per population) around Europe to investigate the cross-species amplification success of these loci: $S$. trutta samples (n $=5$ ) were from Poland, Scotland and three locations in Finland; S. alpinus samples $(\mathrm{n}=5)$ were from Russia, Norway, Scotland and two locations in Finland; and T. thymallus samples $(\mathrm{n}=5)$ were from Norway, Russia, Slovenia and two locations in Finland. Genomic DNA was extracted using ethanol-preserved tissue samples and either a salt extraction protocol [60] or a silica-based method [61].

\section{Amplification and sequencing of the loci}

Details of all primers used in this study are presented in Additional file 1. PCR amplifications were carried out in a total volume of $20 \mu \mathrm{l}$ as outlined in Ryynänen and Primmer [62] and using the primers and annealing temperatures outlined in Additional file 1. In general, all PCR programs were first optimized using the 'touchdown' PCR protocol described in [63], except that the extension step was $45 \mathrm{~s}$ at $72^{\circ} \mathrm{C}$. More specific PCR programs were then used for those loci which produced clear PCR products in the initial amplifications.

As PCR amplifications with primers designed in sequences of non-salmonid species generated multiple fragments in most of the loci, re-PCR amplifications were performed for PCR bands extracted from agarose gels (see Additional file 1) to obtain a single PCR product for sequencing. The initial PCR products were visualized on $1-2 \%$ agarose gels stained with ethidium bromide, and the strongest band was selected to represent the amplicon of the particular locus. A small piece of gel including the desired PCR product was pierced with a plastic pipette tip and, to elute the DNA fragments, the gel piece was dissolved in $50 \mu \mathrm{l} \mathrm{of} \mathrm{H}_{2} \mathrm{O}$ and incubated for at least one hour at room temperature. The re-PCR amplification was then performed with the same primers and protocol as before, except for reducing the number of PCR cycles to 30 and using 1-2 $\mu \mathrm{l}$ of the eluted PCR fragment as a template.

The PCR products were cleaned with GFX $^{\mathrm{TM}}$ DNA purification columns (Amersham Biosciences) or Montage ${ }^{\circledast}$ PCR $\mu 96$ Plates (Millipore) to remove unincorporated nucleotides and primers before direct sequencing. The PCR products were then cycle sequenced in both directions using the BigDye Terminator Cycle Sequencing Ready Reaction Kit 1.0 premix (PE Biosystems) as recommended by the manufacturer, using one of the original PCR primers in turn (Additional file 1) as sequencing primers. After sequencing, the products were purified using Sephadex spin columns (Amersham Biosciences) or Montage ${ }^{\circledast} \mathrm{SEQ}_{96}$ Plates (Millipore), and electrophoresed with an ABI 377 automated sequencer (PE Biosystems) following the manufacturer's recommendations.

\section{Data analysis}

Sequenced loci from different populations were basecalled and aligned using the 'SNP pipeline' [21] - accessible from SNP analysis [64] web server- which employs the Phred/Phrap/PolyPhred series of base-calling, alignment and SNP identification programs [65-67]. All putative SNP sites, either heterozygous or homozygous, were also 
inspected and evaluated manually and only approved as 'true SNPs' if they met at least one of the following criteria: high-quality sequences (phred score $\geq 20$ ) of the rarer nucleotide variant obtained (i) in one or more individuals in both directions (69.2\% of the SNPs observed), (ii) in one direction for at least two individuals $(23.1 \%)$, or (iii) in one individual in one direction in a region of high sequence quality $(7.7 \%)$. The classification of validated SNPs in other salmonids was $38.7 \%, 22.6 \%$ and $38.7 \%$ respectively. Low-quality single-read sequence regions were excluded from all analyses. Candidate sequences obtained with the primers designed in non-salmonid fish sequences were subjected to a Blast homology search [68] against GenBank [42] and the Atlantic Salmon Gene Index [36] to reveal putative homologous genes from the salmon genome.

Nucleotide diversities for the successfully sequenced PCR fragments were estimated using the formula 'theta' $=K /[L$ $\left.{ }^{*}\left[1^{-1}+2^{-1}+3^{-1}+\ldots+(n-1)^{-1}\right]\right]$, where $K$ is the number of observed polymorphic sites, $L$ is the total length of the sequence (in bp) and $n$ is the total number of chromosomes screened. The formula corrects for different sequence lengths and variation in the number of gene copies analysed $[69,70]$. The overall nucleotide diversity estimate was calculated by averaging the number of loci over all screened (ranged from 8 to 30; Table 2). As the analysed transferrin locus is reported to be under selective constraints in salmonids [55], it was excluded in the estimation of the overall nucleotide diversity.

\section{Authors' contributions}

HJR carried out the molecular genetic analyses, performed the data analysis and drafted the manuscript. CRP conceived the study, participated in its design and helped to draft the manuscript. Both authors read and approved the final manuscript.

\section{Additional material}

\section{Additional file 1}

Details of loci, derived from different teleost fish species, tested in the initial SNP screening phase. Indicators $i$-iv refer to fragments amplified from the same gene. Data provides detailed information of the different loci tested in the initial SNP screening phase in this study.

Click here for file

[http://www.biomedcentral.com/content/supplementary/14712164-7-192-S1.doc]

\section{Additional file 2}

Details of the polymorphic sites detected at the sequenced fragments in fifteen Atlantic salmon populations. Overlapping fragments from the same gene have been combined as one index. Population abbreviations are given in Figure 1. Details of these SNPs have been included the sequences submitted to GenBank with the accession numbers [GenBank:DQ834848DQ834872]. Data provides detailed information of the observed polymorphic sites in the analyzed loci.

Click here for file

[http://www.biomedcentral.com/content/supplementary/14712164-7-192-S2.doc]

\section{Acknowledgements}

We would like to thank Paula Lehtonen and Leena Laaksonen for their excellent technical assistance with this work, and Ben Hayes for sharing unpublished results. P. Bruzyan, H. Hirvonen, T. King, J. Piiroinen, S. Suznik, J. Taggart, S. Titov and A. Walker kindly provided tissue or DNA samples from the salmonid populations analyzed in this study. Financial support was obtained from the University of Helsinki and the Finnish Academy (CRP), and also from the Finnish Graduate School of Population Genetics (HJR).

\section{References}

I. Schlötterer C: The Evolution of Molecular Markers - Just a Matter of Fashion? Nature Reviews Genetics 2004, 5:63-69.

2. Brumfield RT, Beerli P, Nickerson DA, Edwards SV: The utility of single nucleotide polymorphisms in inferences of population history. Trends in Ecology \& Evolution 2003, 18:249-256.

3. Morin PA, Luikart G, Wayne RK, the SNP workshop group: SNPs in ecology, evolution and conservation. Trends in Ecology \& Evolution 2004, 19:208-216.

4. The International SNP Map Working Group: A map of human genome sequence variation containing 1.42 million single nucleotide polymorphisms. Nature 2001, 409:928-933.

5. Syvänen A-C: Accessing genetic variation: genotyping single nucleotide polymorphisms. Nature Reviews Genetics 200I, 2:930-942.

6. Glaubitz JC, Rhodes OE, Dewoody JA: Prospects for inferring pairwise relationships with single nucleotide polymorphisms. Molecular Ecology 2003, I 2:1039-1047.

7. Marth G, Yeh R, Minton M, Donaldson R, Li Q, Duan S, Davenport R, Miller R, Kwok P: Single-nucleotide polymorphisms in the public domain: how useful are they? Nature Genetics 200I, 27:37I-372.

8. Chen X, Sullivan P: Single nucleotide polymorphism genotyping: biochemistry, protocol, cost and throughput. Pharmacogenomics Journal 2003, 3:77-96.

9. Wang DG, Fan J-B, Siao C-J, Berno A, Young P, Sapolsky R, Ghandour G, Perkins N, Winchester E, Spencer J, Kruglyak L, Stein L, Hsie L, Topaloglou T, Hubbell E, Robinson E, Mittmann M, Morris MS, Shen N, Kilburn D, Rioux J, Nusbaum C, Rozen S, Hudson TJ, Lipshutz R, Chee M, Lander ES: Large-scale identification, mapping, and genotyping of single-nucleotide polymorphisms in the human genome. Science 1998, 280:1077-1082.

10. Nielsen R: Estimation of population parameters and recombination rates from single nucleotide polymorphisms. Genetics 2000, I 54:93|-942.

II. Kuhner MK, Yamato J, Felsenstein J: Maximum Likelihood Estimation of Recombination Rates From Population Data. Genetics 2000, I 56: I393-1401.

12. Lindblad-Toh K, Winchester E, Daly MJ, Wang DG, Hirschhorn JN, Laviolette J-P, Ardlie K, Reich DE, Robinson E, Sklar P, Shah N, Thomas D, Fan J-B, Gingeras T, Warrington J, Patil N, Hudson TJ, Lander ES: Large-scale discovery and genotyping of single-nucleotide polymorphisms in the mouse. Nature Genetics 2000, 24:38I-386.

13. Hoskins RA, Phan AC, Naeemuddin M, Mapa FA, Ruddy DA, Ryan JJ, Young LM, Wells T, Kopczynski C, Ellis MC: Single Nucleotide 
Polymorphism markers for genetic mapping in Drosophila melanogaster. Genome Research 200 I, I I:I I00-I II3.

14. Vignal A, Milana D, SanCristobala M, Eggenb A: A review on SNP and other types of molecular markers and their use in animal genetics. Genetics Selection Evolution 2002, 34:275-305.

15. Fries R, Durstewitz G: Digital DNA signatures for animal tagging. Nature Biotechnology 200I, 19:508.

16. Primmer CR, Borge T, Lindell J, Saetre G-P: Single-nucleotide polymorphism characterization in species with limited available sequence information: high nucleotide diversity revealed in the avian genome. Molecular Ecology 2002, I I:603-6 I2.

17. Belfiore NM, Hoffman FG, Baker RJ, Dewoody JA: The use of nuclear and mitochondrial single nucleotide polymorphisms to identify cryptic species. Molecular Ecology 2003, I 2:20I I-20I7.

18. Saetre G-P, Borge T, Lindroos K, Haavie J, Sheldon BC, Primmer C, Syvänen A-C: Sex chromosome evolution and speciation in Ficedula flycatchers. Proceedings of the Royal Society B: Biological Sciences 2003, 270:53-59.

19. Borge T, Lindroos K, Nadvornik P, Syvänen A-C, Saetre G-P: Amount of introgression in flycatcher hybrid zones reflects regional differences in pre and post-zygotic barriers to gene exchange. Journal of Evolutionary Biology 2005, 18:1416-1424.

20. Seddon JM, Parker HG, Ostrander EA, Ellegren H: SNPs in ecological and conservation studies: a test in the Scandinavian wolf population. Molecular Ecology 2005, I4:503-5II.

21. Buetow KH, Edmonson MN, Cassidy AB: Reliable identification of large numbers of candidate SNPs from public EST data. Nature Genetics 1999, 21:323-325.

22. Bensch S, Åkesson S, Irwin DE: The use of AFLP to find an informative SNP: genetic differences across a migratory divide in willow warblers. Molecular Ecology 2002, I I:2359-2366.

23. Nicod J-C, Largiader CR: SNPs by AFLP (SBA): a rapid SNP isolation strategy for non-model organisms. Nucleic Acids Research 2003, 31:el9.

24. Palumbi $S$, Baker $C$ : Contrasting population structure from nuclear intron sequences and mtDNA of humpback whales. Molecular Biology and Evolution 1994, I I:426-435.

25. Lyons LA, Laughlin TF, Copeland NG, Jenkins NA, Womack JE, O'Brien S): Comparative anchor tagged sequences (CATS) for integrative mapping of mammalian genomes. Nature Genetics 1997, I 5:47-56.

26. Hassan M, Lemaire C, Fauvelot C, Bonhomme F: Seventeen new exon-primed intron-crossing polymerase chain reaction amplifiable introns in fish. Molecular Ecology Notes 2002, 2:334-340.

27. Tao WJ, Boulding EG: Associations between single nucleotide polymorphisms in candidate genes and growth rate in Arctic charr (Salvelinus alpinus L.). Heredity 2003, 91:60-69.

28. Aitken N, Smith S, Schwarz C, Morin PA: Single nucleotide polymorphism (SNP) discovery in mammals: a targeted-gene approach. Molecular Ecology 2004, 13:|423-|43|.

29. Cossins AR, Crawford DL: Fish as models for environmental genomics. Nature Reviews Genetics 2005, 6:324-333.

30. Hayes B, Sonesson AK, Gjerde B: Evaluation of three strategies using DNA markers for traceability in aquaculture species. Aquaculture 2005, 250:70-8I.

31. Davey GC, Caplice NC, Martin SA, Powell R: A survey of genes in the Atlantic salmon (Salmo salar) as identified by expressed sequence tags. Gene 200I, 263:12I-130.

32. Rise ML, von Schalburg KR, Brown GD, Mawer MA, Devlin RH, Kuipers N, Busby M, Beetz-Sargent M, Alberto R, Gibbs AR, Hunt P, Shukin R, Zeznik JA, Nelson C, Jones SRM, Smailus DE, Jones SJM, Schein JE, Marra MA, Butterfield YSN, Stott JM, Ng SHS, Davidson WS, Koop BF: Development and application of a salmonid EST database and CDNA microarray: data mining and interspecific hybridization characteristics. Genome Research 2004, 14:478-490.

33. Thorsen J, Zhu B, Frengen E, Osoegawa K, de Jong PJ, Koop BF, Davidson WS, Hoyheim B: A highly redundant BAC library of Atlantic salmon (Salmo salar): an important tool for salmon projects. BMC Genomics 2005, 6:50.

34. Norwegian Salmon Genome Project [http://www.salmonge nome.no]

35. GRASP (The Genomic Research on Atlantic Salmon Project) [http://web.uvic.ca/cbr/grasp/]
36. TIGR A. salmon Gene Index [http://www.tigr.org/tigr-scripts/tgi/ $T$ index.cgi?species=salmon]

37. Smith CT, Elfstrom CM, Seeb LW, Seeb JE: Use of sequence data from rainbow trout and Atlantic salmon for SNP detection in Pacific salmon. Molecular Ecology 2005, 1 4:41 93-4203.

38. Gut IG, Lathrop MG: Duplicating SNPs. Nature Genetics 2004, 36:789-790.

39. Oakley TH, Phillips RB: Phylogeny of salmonine fishes based on growth hormone introns: Atlantic (Salmo) and Pacific (Oncorhynchus) salmon are not sister taxa. Molecular Phylogenetics and Evolution 1999, I I:38I-393.

40. Phillips RB, Matsuoka MP, Konkol NR, McKay S: Molecular Systematics and Evolution of the Growth Hormone Introns in the Salmoninae. Environmental Biology of Fishes 2004, 69:433-440.

41. Ryynänen HJ, Primmer CR: Distribution of genetic variation in the growth hormone I gene in Atlantic salmon (Salmo salar) populations from Europe and North America. Molecular Ecology 2004, I 3:3857-3869.

42. Benson DA, Karsch-Mizrachi I, Lipman DJ, Ostell J, Wheeler DL: GenBank: update. Nucleic Acids Research 2004, 32:D23-26.

43. Volff J-N: Genome evolution and biodiversity in teleost fish. Heredity 2005, 94:280-294.

44. Venkatesh B: Evolution and diversity of fish genomes. Current Opinion in Genetics \& Development 2003, 13:588-592.

45. Prince VE, Pickett FB: Splitting pairs: The diverging fates of duplicated genes. Nature Reviews Genetics 2002, 3:827-837.

46. Fredman D, White SJ, Potter S, Eichler EE, Den Dunnen JT, Brookes A): Complex SNP-related sequence variation in segmental genome duplications. Nature Genetics 2004, 36:86I-866.

47. Dvornyk V, Sirvio A, Mikkonen M, Savolainen O: Low nucleotide diversity at the pall locus in the widely distributed Pinus sylvestris. Molecular Biology and Evolution 2002, 19:179-188.

48. Yu J, Hu S, Wang J, Wong GK-S, Li S, Liu B, Deng Y, Dai L, Zhou Y, Zhang $X$, Cao M, Liu J, Sun J, Tang J, Chen Y, Huang X, Lin W, Ye C, Tong W, Cong L, Geng J, Han Y, Li L, Li W, Hu G, Huang X, Li W, Li J, Liu Z, Li L, Liu J, Qi Q, Liu J, Li L, Li T, Wang X, Lu H, Wu T, Zhu M, Ni P, Han H, Dong W, Ren X, Feng X, Cui P, Li X, Wang H, Xu X, Zhai W, Xu Z, Zhang J, He S, Zhang J, Xu J, Zhang K, Zheng X, Dong J. Zeng W, Tao L, Ye J, Tan J, Ren X, Chen X, He J, Liu D, Tian W, Tian C, Xia H, Bao Q, Li G, Gao H, Cao T, Wang J, Zhao W, Li P, Chen W, Wang $X$, Zhang $Y$, Hu J, Wang J, Liu S, Yang J, Zhang G, Xiong Y, Li Z, Mao L, Zhou C, Zhu Z, Chen R, Hao B, Zheng W, Chen S, Guo W, Li G, Liu S, Tao M, Wang J, Zhu L, Yuan L, Yang H: A Draft Sequence of the Rice Genome (Oryza sativa L. ssp. indica). Science 2002, 296:79-92.

49. Ståhl G: Genetic population structure of Atlantic salmon. In Population Genetics and Fishery Management Edited by: Ryman N, Utter F. Seattle: University of Washington Press; 1987:12I-140.

50. Hewitt GM: Some genetic consequences of ice ages, and their role in divergence and speciation. Biological Journal of the Linnean Society 1996, 58:247-276.

5I. Palo JU, Schmeller DS, Laurila A, Primmer CR, Kuzmin SL, Merila J: High degree of population subdivision in a widespread amphibian. Molecular Ecology 2004, I 3:263 I-2644.

52. Zhao Z, Fu Y-X, Hewett-Emmett D, Boerwinkle E: Investigating single nucleotide polymorphism (SNP) density in the human genome and its implications for molecular evolution. Gene 2003, 3 I 2:207-2। 3 .

53. Cargill M, Altshuler D, Ireland J, Sklar P, Ardlie K, Patil N, Lane CR, Lim EP, Kalyanaraman N, Nemesh J, Ziaugra L, Friedland L, Rolfe A, Warrington J, Lipshutz R, Daley GQ, Lander ES: Characterization of single-nucleotide polymorphisms in coding regions of human genes. Nature Genetics 1999, 22:231-238.

54. Halushka MK, Fan J-B, Bentley K, Hsie L, Shen N, Weder A, Cooper $R$, Lipshutz R, Chakravarti A: Patterns of single-nucleotide polymorphisms in candidate genes for blood-pressure homeostasis. Nature Genetics 1999, 22:239-247.

55. Ford MJ: Molecular evolution of transferrin: Evidence forpositive selection in Salmonids. Molecular Biology and Evolution 200I, I8:639-647.

56. Antunes A, Templeton AR, Guyomard R, Alexandrino P: The role of nuclear genes in intraspecific evolutionary inference: Genealogy of the transferrin gene in the brown trout. Molecular Biology and Evolution 2002, 19:1272-1287.

57. Koskinen MT, Nilsson J, Veselov AJ, Potutkin AG, Ranta E, Primmer $\mathrm{CR}$ : Microsatellite data resolve phylogeographic patterns in 
European grayling, Thymallus thymallus, Salmonidae. Heredity 2002, 88:39|-40।

58. Bernatchez L: The Evolutionary History of Brown Trout (Salmo trutta L.) Inferred from Phylogeographic, Nested Clade, and Mismatch Analyses of Mitochondrial DNA Variation. Evolution 200I, 55:35I-379.

59. Rozen S, Skaletsky HJ: Primer3 on the WWW for general users and for biologist programmers. In Bioinformatics Methods and Protocols: Methods in Molecular Biology Edited by: Krawetz S, Misener S. Totowa, NJ: Humana Press; 2000:365-386.

60. Aljanabi SM, Martinez I: Universal and rapid salt-extraction of high quality genomic DNA for PCR-based techniques. Nucleic Acid Research 1997, 25:4692-4693.

61. Elphinstone MS, Hinten GN, Anderson MJ, Nock CJ: An inexpensive and high-throughput procedure to extract and purify total genomic DNA for population studies. Molecular Ecology Notes 2003, 3:317-320.

62. Ryynänen HJ, Primmer CR: Primers for sequence characterization and polymorphism detection in the Atlantic salmon (Salmo salar) growth hormone I (GHI) gene. Molecular Ecology Notes 2004, 4:664-667.

63. Koskinen MT, Primmer CR: Cross-species amplification ofsalmonid microsatellites which reveal polymorphism in European and Arctic grayling, Salmonidae: Thymallus spp. Hereditas 1999, 131:171-176.

64. SNP analysis [http://lpgws.nci.nih.gov/perl/snp/snp cgi.pl]

65. Nickerson D, Tobe V, Taylor S: PolyPhred: automating the detection and genotyping of single nucleotide substitutions using fluorescence-based resequencing. Nucleic Acids Research 1997, 25:2745-275I.

66. Ewing B, Green P: Base-Calling of Automated Sequencer Traces Using Phred. II. Error Probabilities. Genome Research 1998, 8: 186-194.

67. Ewing B, Hillier L, WendI MC, Green P: Base-Calling of Automated Sequencer Traces Using Phred. I. Accuracy Assessment. Genome Research 1998, 8: I75-185.

68. Altschul S, Madden T, Schaffer A, Zhang J, Zhang Z, Miller W, Lipman D: Gapped BLAST and PSI-BLAST: a new generation of protein database search programs. Nucleic Acids Research 1997, 25:3389-3402.

69. Watterson GA: On the number of segregating sites in genetical models without recombination. Theoretical Population Biology 1975, 7:256-76.

70. Nei M: Molecular Evolutionany Genetics. New York Columbia University Press; 1987.

7I. Schmid M, Nanda I, Guttenbach M, Steinlein C, Hoehn H, Schartl M, Haaf T, Weigend S, Fries R, Buerstedde J-M, Wimrners K, Burt DW, Smith HJ, A'Hara S, Law A, Griffin DK, Bumstead N, Kaufman J, Thomson PA, Burke T: First Report on Chicken Genes and Chromosomes 2000. Cytogenetics \& Cell Genetics 2000, 90:169-218

72. Kirkness EF, Bafna V, Halpern AL, Levy S, Remington K, Rusch DB, Delcher AL, Pop M, Wang W, Fraser CM, Venter JC: The Dog Genome: Survey Sequencing and Comparative Analysis. Science 2003, 301: 1898-1903.

73. Schmid KJ, Sorensen TR, Stracke R, Torjek O, Altmann T, MitchellOlds $T$, Weisshaar B: Large-scale identification and analysis of genome-wide single-nucleotide polymorphisms for mapping in Arabidopsis thaliana. Genome Research 2003, 13:1250-1257.

74. Russell J, Booth A, Fuller J, Harrower B, Hedley P, Machray G, Powell $\mathrm{W}$ : A comparison of sequence-based polymorphism and haplotype content in transcribed and anonymous regions of the barley genome. Genome 2004, 47:389-398.
Publish with Biomed Central and every scientist can read your work free of charge

"BioMed Central will be the most significant development for disseminating the results of biomedical research in our lifetime. "

Sir Paul Nurse, Cancer Research UK

Your research papers will be:

- available free of charge to the entire biomedical community

- peer reviewed and published immediately upon acceptance

- cited in PubMed and archived on PubMed Central

- yours - you keep the copyright

Submit your manuscript here:

http://www.biomedcentral.com/info/publishing_adv.asp
BiolMedcentral 